Int. J. Electrochem. Sci., 15 (2020) 12491 - 12503

International Journal of

ELECTROCHEMICAL

SCIENCE

WWW.electrochemsci.org

\title{
Process Localization at the Electrolyte Jet Machining for Additive Manufacturing
}

\author{
Yangpei Zhao ${ }^{1}$, Hui Fan ${ }^{2, *}$ \\ ${ }^{1}$ Jiangsu Vocational Institute of Architectural Technology, Xuzhou, 221116, China \\ ${ }^{2}$ School of Mechanical and Electrical Engineering, Jiangsu Normal University, Xuzhou, 221116, \\ China \\ *E-mail: xzfanhui@163.com
}

doi: $10.20964 / 2020.12 .61$

Received: 30 July 2020 / Accepted: 27 Sepember 2020 / Published: 31 October 2020

\begin{abstract}
Rapid prototyping manufacturing (RPM) has received high interest in the field of engineering. However, the current processing methods are complex and expensive, and it is difficult to prepare nanostructure materials, which limits further applications. Electrolyte jet machining is an emerging precision manufacturing technology that uses an electrolyte jet to generate a metallic deposit with a high deposition rate and a nanocrystalline material structure. This paper is devoted to developing a new type of prototyping technology that employs electrolyte jet machining to form a micro-metallic part with a nanocrystalline material. The new manufacturing method is expected to cover the shortcomings of the current RPM technology. The concept of incorporating electrolyte jet machining and rapid prototyping technology as well as an experimental practice are introduced. It is believed that the forming precision of electrolyte jet machining is determined by process localization, which is mainly influenced by the technical parameters, including the nozzle diameter, jet distance, current density, and nozzle scan speed. The technical parameters are studied regarding their effects on the process localization. It is proven that the application of a small nozzle diameter, low current density and fast scan speed is highly favourable for reducing the size of the electroformed spot and for improving process localization. A group of nanocrystalline copper parts with a good shape have been produced using optimized parameters.
\end{abstract}

Keywords: Rapid prototyping manufacturing (RPM), electrolyte jet machining, nanocrystalline material, copper parts, process localization,

\section{$\underline{\text { FULL TEXT }}$}

(C) 2020 The Authors. Published by ESG (www.electrochemsci.org). This article is an open access article distributed under the terms and conditions of the Creative Commons Attribution license (http://creativecommons.org/licenses/by/4.0/). 